\title{
Effect of stylet angulation and endotracheal tube camber on time to intubation with the GlideScope ${ }^{\circledR}$
}

\author{
[Effet de l'angulation du mandrin et de la cambrure de la sonde endotrachéale \\ sur le temps requis pour l'intubation avec le GlideScope®]
}

Philip M. Jones MD FRCPC, Timothy P. Turkstra MD FRCPC, Kevin P. Armstrong MD FRCPC, Paidrig M. Armstrong MD FRCPC, Richard A. Cherry MD FRCPC, Jason Hoogstra MD FRCPC, Christopher C. Harle MBChB FRCA

Purpose: The GlideScope ${ }^{\circledR}$ videolaryngoscope usually provides excellent glottic visualization, but directing an endotracheal tube (ETT) through the vocal cords is sometimes difficult. The goal of the study was to determine which of two ETT angles $\left(60^{\circ}\right.$ vs $\left.90^{\circ}\right)$ and cambers (forward vs reverse) was better, as determined by time to intubation (TTI).

Methods: Two hundred patients requiring orotracheal intubation for elective surgery were randomly allocated to one of four groups: A) $90^{\circ}$ angle, forward camber; B) $90^{\circ}$ angle, reverse camber; C) $60^{\circ}$ angle, forward camber; D) $60^{\circ}$ angle, reverse camber. Time to intubation was assessed by a blinded observer. Operators were blinded until the point of intubation. A visual analogue scale (VAS) assessed the ease of intubation. The number of intubation attempts, number of failures, glottic grades, and use of external laryngeal manipulation were recorded.

Results: The angle of the ETT had an impact on TTI but camber did not. The $90^{\circ}$ angle demonstrated a I3\% faster TTI than the $60^{\circ}$ angle $(47.1 \pm 21.2 \mathrm{sec} v 54.4 \pm 28.2 \mathrm{sec}, P=0.042)$, and it resulted in easier intubation (VAS I6.4 $14.2 \mathrm{~mm}$ vs 27.3 $\pm 23.5 \mathrm{~mm}, P=0.000 \mathrm{I})$. The overall incidence of a grade I or 2 Cormack-Lehane glottic view was $99 \%$.

Conclusions: In a heterogeneous group of operators and patients intubated with the GlideScope ${ }^{\circledR}$, a $90^{\circ}$ ETT angle provided the best result and should be the initial configuration. The camber of the ETT does not affect the time to intubation.

CAN J ANESTH $2007 / 54: 1 /$ pp 21-27
Objectif : Le vidéo-laryngoscope GlideScope ${ }^{\circledR}$ offre en général une excellente visualisation glottique ; toutefois, il est parfois difficile d'orienter la sonde endotrachéale (SET) entre les cordes vocales. Le but de cette étude était de déterminer lequel de deux angles de SET $\left(60^{\circ}\right.$ vs $\left.90^{\circ}\right)$ et quelle cambrure (avant vs arrière) étaient les meilleurs, déterminés selon le temps requis pour l'intubation (TRI).

Méthodes: Deux cents patients nécessitant une intubation oro-trachéale pour une chirurgie réglée ont été répartis en quatre groupes de façon aléatoire : a) angulation de $90^{\circ}$, cambrure avant ; b) angulation de $90^{\circ}$, cambrure arrière ; c) angulation de $60^{\circ}$, cambrure avant; d) angulation de $60^{\circ}$, cambrure arrière. Le temps requis pour l'intubation était estimé par un observateur ignorant le groupe d'allocation. Les opérateurs ont été tenus ignorants du groupe d'allocation jusqu'à l'intubation. Une échelle visuelle analogique (VAS) permettait d'estimer la facilité d'intubation. Le nombre de tentatives d'intubation, d'échecs, les grades glottiques ainsi que l'utilisation de manipulation laryngée externe étaient notés.

Résultats : L'angulation de la SET a eu un impact sur le TRI mais pas la cambrure. Avec une angulation de $90^{\circ}$, le TRI était de $13 \%$ plus rapide qu'avec une angulation de $60^{\circ}(47, I \pm 21,2 \mathrm{sec}$ vs $54,4 \pm 28,2 \mathrm{sec}, P=0,042$ ), et l' intubation était plus facile (VAS $16,4 \pm 14,2 \mathrm{~mm}$ vs $27,3 \pm 23,5 \mathrm{~mm}, P=0,000 \mathrm{I}$ ). L'incidence globale d'une visualisation glottique Cormack-Lehane de grade I ou 2 a été de $99 \%$.

Conclusions: Dans un groupe hétérogène d'opérateurs et de patients intubés avec le GlideScope ${ }^{\circledR}$, une angulation de la SET de $90^{\circ}$ offre le meilleur résultat et devrait être la configuration initiale. La cambrure de la SET n'affecte pas le temps requis pour l'intubation.

From the Department of Anesthesia \& Perioperative Medicine, University of Western Ontario, London, Ontario, Canada. Address correspondence to: Dr. Philip M. Jones, Department of Anesthesia \& Perioperative Medicine, London Health Sciences Centre

- University Hospital, Room C3-110, 339 Windermere Road, London, Ontario N6A 5A5, Canada. Phone: 519-685-8500;

Fax: 519-663-2957; E-mail: philip.jones@lhsc.on.ca

Disclosure statement: This study was internally funded. None of the authors have any conflicts to report. Accepted for publication September 11, 2006.

Revision accepted October 2, 2006. 
$\mathrm{T}$

HE GlideScope ${ }^{\circledR}$ videolaryngoscope (GVL; Verathon Medical Inc., Bothell, WA, USA) is a novel intubating device which uses a high-resolution camera embedded into a plastic laryngoscope blade. It consistently provides a good glottic view ${ }^{1}$, but directing the endotracheal tube (ETT) through the vocal cords is sometimes difficult. ${ }^{2,3}$ Because of the $60^{\circ}$ distal anterior curvature of the GVL blade, ETTs must have stylets inserted so that the ETT's distal tip can be positioned anteriorly. ${ }^{2}$ Various authors have recommended different angles of the ETT to optimally place it into the trachea, including matching the blade's $60^{\circ}$ angle, ${ }^{1,4}$ using a "J-shaped" ETT, or configuring the ETT with a $90^{\circ}$ bend. $^{2}$

Regardless of the angulation used, the natural camber of the ETT tends to direct the distal tip of the ETT even further anteriorly when the stylet is retracted - possibly impeding the ETT from advancing into the trachea. Thus, some practitioners have loaded the stylet in the ETT in a "reverse camber" configuration, ${ }^{6}$ which may direct the distal tip of the ETT posteriorly upon stylet retraction, and hence more directly into the trachea.

The optimum angulation of the distal portion of the ETT is unknown, as is the best configuration of the natural memory of the ETT (forward or reverse camber). Therefore, a prospective, randomized, singleblinded trial was conceived to address both of these questions. The priority of the trial design was to include a heterogeneous group of patients as well as a diverse group of GVL operators, so that the results of the trial would be broadly applicable to clinical practice.

\section{Methods}

After obtaining local Research Ethics Board approval, patients were screened for enrolment in the trial. Patients were eligible for inclusion if they were at least $18 \mathrm{yr}$ old and scheduled for elective surgery requiring orotracheal intubation. Patients were excluded if they had a known difficult airway, required rapid sequence induction, or if the attending anesthesiologist considered use of the GVL to be contraindicated. In order to obtain a group of operators with a broad range of GVL experience, anesthesiologists and anesthesiology residents were eligible to be operators if they had successfully performed at least three GVL intubations. An operator was arbitrarily defined as being experienced after having successfully completed more than 15 GVL intubations. The study took place at all three teaching hospitals in London, Ontario, from November 2005 to March 2006, and involved patients having surgery in virtually every surgical discipline. Written informed consent was obtained from patients and operators.

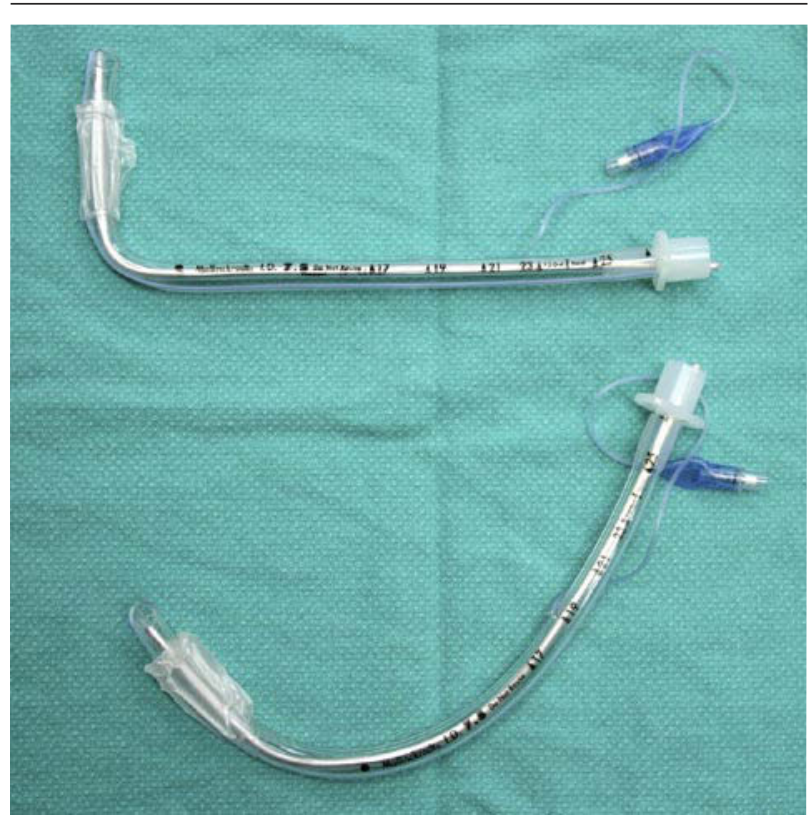

FIGURE 1 The two endotracheal tube (ETT) angulations that were investigated are shown: $90^{\circ}$ (top) and $60^{\circ}$ (bottom). The $90^{\circ}$ angle was created $8 \mathrm{~cm}$ from the distal tip of the ETT.

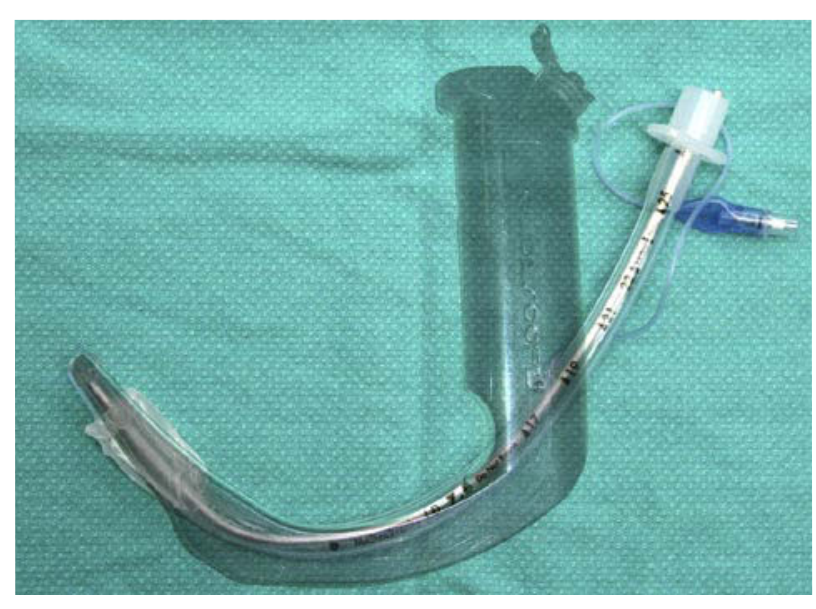

FIGURE 2 The $60^{\circ}$ angle was constructed using the GlideScope ${ }^{\circledR}$ blade as a template. The endotracheal tube (ETT) configuration copied the shape of the GlideScope ${ }^{\circledR}$ up to the point at which the blade met the handle. Thereafter, the ETT was straight.

The two ETT angles investigated followed the two most commonly used angles in our local practice (Figure 1). The $90^{\circ}$ angle was fashioned at $8 \mathrm{~cm}$ from the distal end of the ETT and there was no other angulation of the ETT. The $60^{\circ}$ angle was a slight modi- 
fication of the manufacturer's recommendation ${ }^{4}-$ an angle of approximately $60^{\circ}$ was created at $8 \mathrm{~cm}$ from the distal end of the ETT, and the proximal portion of the ETT continued a gentle concave angulation that followed the shape of the GVL blade until the point at which the blade met the handle (Figure 2).

The trial consisted of a $2 \times 2$ factorial design to investigate all four possible combinations of angles $\left(90^{\circ} v s 60^{\circ}\right)$ and cambers (forward vs reverse). Patients were randomized to one of four possible groups:

Group 90 Forward: $90^{\circ}$ ETT angle, forward camber Group 90 Reverse: $90^{\circ}$ ETT angle, reverse camber Group 60 Forward: $60^{\circ}$ ETT angle, forward camber Group 60 Reverse: $60^{\circ}$ ETT angle, reverse camber.

The null hypothesis was that there would be no difference in time to intubation (TTI) between the groups.

Patients were randomly assigned to one of the four groups using computer-generated codes enclosed within opaque envelopes that were opened just before the patients entered the operating room. Each envelope also contained a paper template that allowed precise duplication of the pre-specified tube angle and camber. The attending anesthesiologist chose the ETT size. Using a lubricated malleable stylet, the ETT was configured according to the template by one of the study investigators, who then had no further involvement with that patient's clinical care or outcome assessment. The ETT was concealed by wrapping it in a towel so the GVL operator would be blinded until the operator requested the ETT.

Before taking part in the trial, operators recorded their ETT angle and camber preferences. Patient demographics and Mallampati score ${ }^{7}$ were recorded preoperatively by the attending anesthesiologist. An iv catheter was inserted before arrival in the operating room. Appropriate monitoring for each patient was applied, and pre-oxygenation was performed until an end-tidal oxygen concentration of $\geq 80 \%$ was attained. Induction and maintenance of anesthesia was not standardized. All patients had a non-depolarizing muscle relaxant administered, but the drug and dose were at the discretion of the attending anesthesiologist. After induction, the patient's lungs were ventilated with $100 \%$ oxygen until the operator deemed it appropriate to start the process of intubation. The ETT was then removed from within the towel, unblinding the operator. A GlideScope ${ }^{\circledR}$ laryngoscopy was performed, the patient was intubated and the were lungs ventilated via the ETT. If the operator removed the GVL blade or ETT from the patient's mouth, this was counted as an additional attempt at intubation. Operators were per- mitted to use external laryngeal manipulation in order to improve the glottic view or to facilitate intubation.

The primary outcome was the TTI as measured by a blinded observer. The TTI started when the GVL blade first passed the lips, and ended when the endtidal $\mathrm{CO}_{2}$ attained a value of at least $30 \mathrm{mmHg}$. The blinded observer watched the patient until the assessment began, and he/she then turned so that only the anesthesia monitor was visible (at no point did the observer see the ETT). If the intubation attempt took longer than $150 \mathrm{sec}$, it was deemed a failure and the patient was intubated using a different modality. Failed intubations were included in the analysis (recorded as a TTI of $150 \mathrm{sec}$ ). Pre-specified secondary outcomes for each group included ease of intubation [as recorded by the operator immediately after the intubation on a $100-\mathrm{mm}$ visual analogue scale (VAS)], the number of failures, the number of attempts made (one attempt or more than one attempt), and whether or not external laryngeal manipulation was used. After intubation, the operator recorded the ease of visualization of the glottic structures based on the classification described by Cormack and Lehane $(\mathrm{C} / \mathrm{L}) .{ }^{8}$ The TTI was not divulged to the operator until after the data collection sheet had been completed.

For sample size calculation, a between-group difference of ten seconds in TTI was considered clinically significant. The SD of TTI was estimated from a simulation study that demonstrated a SD of ten seconds, ${ }^{9}$ and a human study that showed a SD of $12 \mathrm{sec} .{ }^{10} \mathrm{~A}$ conservative SD of $14 \mathrm{sec}$ for TTI was employed with standard type I and type II error rates $(\alpha=0.05, \beta=$ 0.20 ). The calculated sample size was 48 per group; a total sample size of 200 patients was selected.

\section{Statistical analysis}

The primary outcome was assessed using two-way ANOVA with the main effects being angle and camber. If there was no significant interaction between the two main effects for the primary outcome, it was decided a priori that all of the data would be pooled and analyzed by the main effects that demonstrated significance. The VAS was analyzed using one-way ANOVA (if both main effects were significant) or Student's $t$ test (if only one main effect was significant). Chi-square or Fisher's exact test were used as appropriate for categorical data. Data are shown as mean \pm SD unless otherwise noted. Results were considered statistically significant when $P<0.05$.

\section{Results}

Two hundred patients were recruited. Baseline demographics and ETT size were similar between study 
TABLE I Demographic data

\begin{tabular}{lllll}
\hline Characteristic & $90^{\circ}$ forward $(n=50)$ & $90^{\circ}$ reverse $(n=50)$ & $60^{\circ}$ forward $(n=49)$ & $60^{\circ}$ reverse $(n=47)$ \\
\hline Age & $47.6(16.6)$ & $53.0(16.7)$ & $50.3(16.9)$ & $48.2(16.4)$ \\
Male (\%) & 42 & 54 & 39 & 47 \\
ASA I/II/III/IV (\%) & $20 / 48 / 12 / 20$ & $18 / 32 / 28 / 22$ & $27 / 27 / 37 / 10$ & $23 / 38 / 26 / 13$ \\
BMI $\left(\mathrm{kg} \cdot \mathrm{m}^{-2}\right)$ & $27.8(6.6)$ & $27.9(5.3)$ & $28.4(5.5)$ & $29.4(6.3)$ \\
Mallampati score & & $52 / 38 / 10 / 0$ & $59 / 31 / 10 / 0$ & $47 / 49 / 4 / 0$ \\
I/II/III/IV (\%) & $70 / 26 / 4 / 0$ & 82 & 88 & 87 \\
Any upper teeth present (\%) & 78 & 8.0 & 7.5 & 7.5 \\
ETT internal diameter (median) & 7.5 & $42(84)$ & $29(59)$ & $33(70)$ \\
Experienced operator $(\%)$ & $34(68)$ & &
\end{tabular}

TABLE II Intubation data

\begin{tabular}{|c|c|c|c|}
\hline & $\begin{array}{l}90^{\circ} \text { group } \\
(n=100)\end{array}$ & $\begin{array}{l}60^{\circ} \text { group } \\
(n=96)\end{array}$ & $P^{*}$ \\
\hline \multicolumn{4}{|l|}{ Glottic grade $\dagger$} \\
\hline I & 91 & 77 & \\
\hline II & 9 & 18 & 0.079 \\
\hline III & 0 & 1 & \\
\hline IV & 0 & 0 & \\
\hline \multicolumn{4}{|l|}{ Attempts at intubation } \\
\hline 1 & 93 & 84 & 0.232 \\
\hline$>1$ & 7 & 12 & \\
\hline Number of failed intubations & 1 & 3 & 0.361 \\
\hline $\begin{array}{l}\text { Use of external laryngeal } \\
\text { manipulation }\end{array}$ & 5 & 18 & 0.003 \\
\hline
\end{tabular}

groups (Table I). Four patients were withdrawn from analysis after randomization: three in the 60 Reverse group (one had surgery cancelled, one operator had not used the GVL at least three times, and one had no TTI recorded on the data entry sheet) and one in the 60 Forward group (surgery cancelled). Fifty-three operators were recruited (64\% experienced). The median number of intubations performed by a single operator was 3.0 (interquartile range $2-4$, range $1-17$ ).

Two-way ANOVA demonstrated a significant main effect on TTI attributable to the angle of the ETT $(\mathrm{F}=4.18, P=0.042)$. There was no significant main effect of camber $(\mathrm{F}=0.81, P=0.370)$, nor was there any interaction between angle and camber $(\mathrm{F}=0.03$, $P=0.864)$. Therefore, the data for the forward and reverse cambers were pooled within each of the two angle groups.
The mean TTI was $13 \%$ lower for the $90^{\circ}$ group $(47.1 \pm 21.2 \mathrm{sec})$ compared to the $60^{\circ}$ group $(54.4$ $\pm 28.2 \mathrm{sec}$ ). To assess the temporal component of the success of intubation, Kaplan-Meier plots were constructed for both angle and camber (Figure 3). When comparing the two angles, there was a significant global improvement in TTI in the $90^{\circ}$ group (particularly after $50 \mathrm{sec}$ ). There was no significant difference in TTI between the two cambers.

The ease of intubation VAS demonstrated that operators found the $90^{\circ}$ group significantly easier to intubate than the $60^{\circ}$ group (Figure 4 ). There was $73 \%$ less use of external laryngeal manipulation in the $90^{\circ}$ group, as well as a trend toward a higher proportion of better glottic grades (Table II).

\section{Discussion}

In a group of heterogeneous operators using the GVL for orotracheal intubation in a diverse cohort of patients, a distal $90^{\circ}$ angulation of the ETT results in an average TTI that is $13 \%$ lower than with a $60^{\circ}$ angulation. The camber of the ETT does not have any impact on TTI. The $90^{\circ}$ angulation was also associated with improved ease of intubation and lower rates of external laryngeal manipulation.

In addition to being superior with respect to TTI, the $90^{\circ}$ ETT was easy to configure since it involved creating only one angle. The angle in the ETT was placed where the "bend here" label is located on a TrachLight ${ }^{\circledR}$ (Laerdal Medical, Toronto, ON, Canada) stylet - making it easy for anesthesia practitioners to replicate the bend. Configuring an ETT that conforms to the shape of the GVL blade takes more time, may be less reproducible, and offers no advantage in TTI or ease of intubation.

The Kaplan-Meier plot showing the percentage of patients intubated as time progressed demonstrates the superiority of the $90^{\circ}$ angle at all time points. 

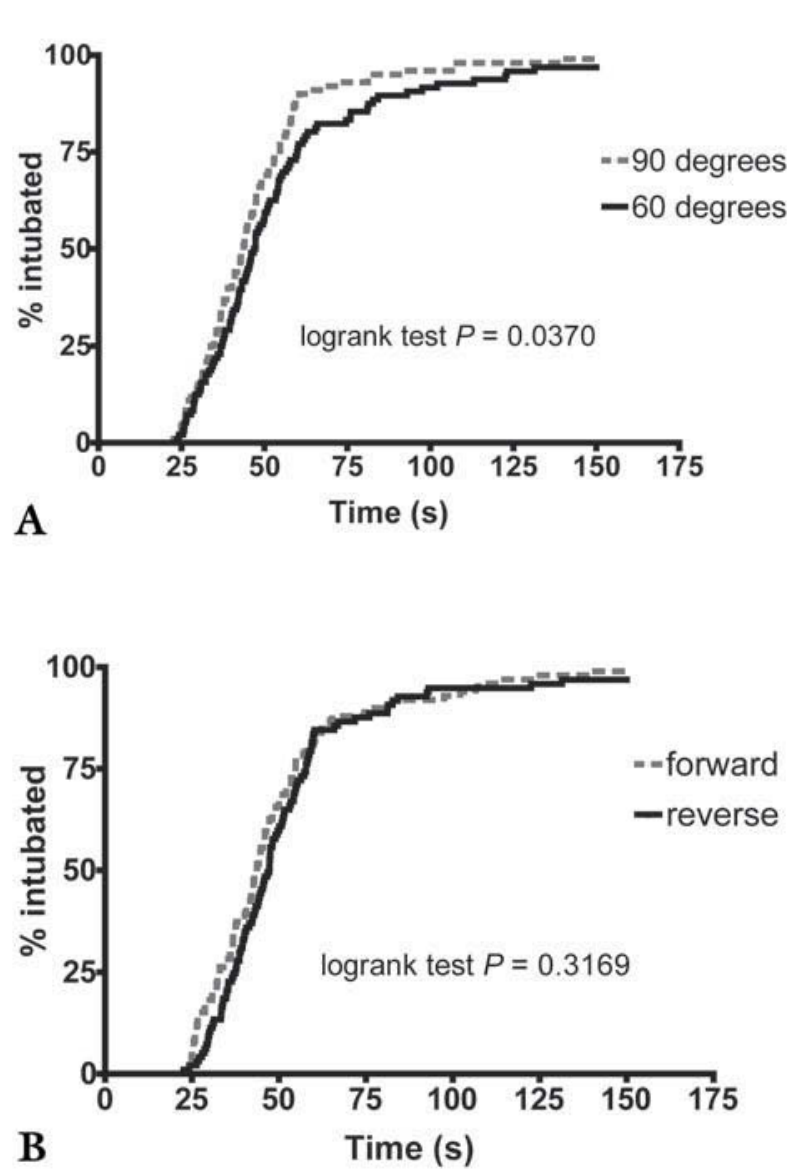

FIGURE 3 Kaplan-Meier plots demonstrating a) the temporal effects of angle; and b) camber on time to intubation.

Interestingly, the largest difference between groups occured at one minute, at which point $87 \%$ of patients in the $90^{\circ}$ group were successfully intubated compared with only $74 \%$ of the $60^{\circ}$ group. Another $22 \mathrm{sec}$ elapsed before $87 \%$ of the patients in the $60^{\circ}$ group were successfully intubated. This difference may have clinical relevance, especially when trying to maintain normoxemia in patients who have a low functional residual capacity, inadequate preoxygenation, or high oxygen consumption. ${ }^{11}$

A common criticism of the GVL has been the difficulty with which an ETT passes through the vocal cords despite excellent glottic visualization. ${ }^{1-3,5,12}$ Based on the TTI and ease of intubation VAS found in this trial, it is likely that the $90^{\circ}$ configuration passes

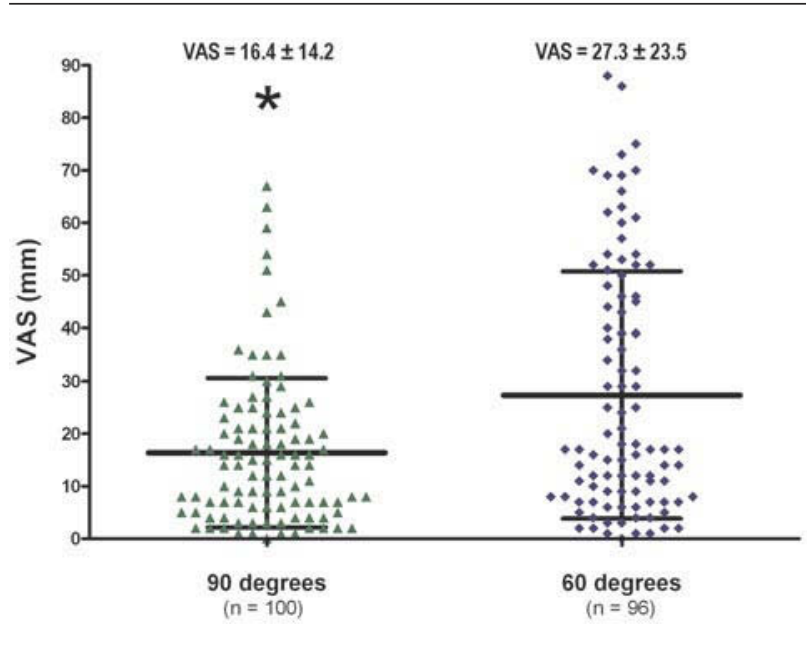

FIGURE 4 Ease of intubation by operators as measured on a $100-\mathrm{mm}$ visual analogue scale (VAS). The markings on the data collection form filled out by the GlideScope ${ }^{\circledR}$ operators was marked "easy" (at $0 \mathrm{~mm}$ ) and "difficult" (at $100 \mathrm{~mm})$. Bars and text indicate mean VAS $\pm \mathrm{SD} .{ }^{*} P=$ 0.0001 compared to $60^{\circ}$ group.

the glottis more easily than does the $60^{\circ}$ configuration. This study has confirmed the excellent glottic view that one regularly obtains with the GVL (Table II). Indeed, $93 \%$ of the patients in the $90^{\circ}$ group had a $\mathrm{C} / \mathrm{L}$ grade 1 glottic view and, overall, $99 \%$ of patients had either a $\mathrm{C} / \mathrm{L} 1$ or 2 glottic view, which is in agreement with previous work by Cooper ${ }^{1}$ and Sun. ${ }^{13}$

Interestingly, there was a trend toward poorer glottic exposure in the $60^{\circ}$ group as only $82 \%$ of patients in the $60^{\circ}$ group had a grade 1 view. This is likely the reason for the increased usage of external laryngeal manipulation in the $60^{\circ}$ group. This could be due to chance alone. However, since the operators knew they were being timed, they did not necessarily fully expose the glottis before inserting the ETT into the mouth. Once the ETT was inserted into the mouth, it is possible that the $60^{\circ}$ configuration might have negatively affected the glottic view upon attempts at tracheal intubation (which was the glottic view recorded in this study) because of an adverse interplay between the ETT shape and the GVL blade/handle. Nonetheless, the GVL produced excellent glottic exposure in both groups, as there was only one patient out of 196 who had a $\mathrm{C} / \mathrm{L}$ grade 3 view, and none who had a $\mathrm{C} / \mathrm{L}$ grade 4 view.

The measurement of TTI was stopped when end-tidal $\mathrm{CO}_{2}$ was observed on the capnograph (as opposed to the time of ETT cuff inflation) which is 
similar to other trials investigating modes of intubation. ${ }^{13-15}$ This approach is clinically meaningful and provides an objective endpoint. If the TTI had stopped when the ETT cuff was inflated or when the GVL blade was removed from the patient's mouth, the observer may have become unblinded by watching the operator intubate the patient, and this could have resulted in biased observations.

Operators were aware that they were participating in a clinical trial and that the intubation was being timed. This fact could have improved clinical performance (the Hawthorne effect). ${ }^{16}$ However, any improvement would likely have been distributed equally between the groups - minimizing the impact of this effect.

Patients with known difficult airways were excluded from this trial, but since the GVL improves glottic visualization in patients with poor $\mathrm{C} / \mathrm{L}$ grades by direct laryngoscopy, ${ }^{1,13}$ it is possible that the findings of this trial (improved performance with the $90^{\circ}$ configuration) would also apply to this subgroup.

Four patients in this trial were not intubated using the GVL within the pre-specified time of $150 \mathrm{sec}$. There was a trend to a higher failure rate in the $60^{\circ}$ group (three failures $v s$ one failure in the $90^{\circ}$ group, $P$ $=0.361)$. Since all four failed GVL intubations demonstrated a $\mathrm{C} / \mathrm{L}$ grade 1 glottic visualization, these failed intubations were secondary to an inability to pass the ETT through the vocal cords. All of the failed intubations occurred with inexperienced operators. Two of the patients in the $60^{\circ}$ group who failed intubation were subsequently intubated successfully with the GVL using the $90^{\circ}$ configuration. The remaining two patients were intubated using direct laryngoscopy by the attending anesthesiologist (no attempt at intubation was made by the attending anesthesiologist using the GVL).

Limitations of this study include the fact that only two ETT configurations were studied. There are an infinite number of angles and pivot points of an ETT that could be tested. The most commonly used configurations in our centre and in the literature were chosen; the $60^{\circ}$ configuration was based on the manufacturer's instructions and previous reports in the literature. ${ }^{1,3}$ Operators may have been biased if they preferred one angulation over the other before the trial started. However, most operators (61\%) expressed a preference for the $60^{\circ}$ angulation prior to the study, making pre-trial bias an unlikely explanation of the difference between the two angles. Finally, the GlideScope ${ }^{\circledR}$ is now available in a second-generation colour model with a slightly smaller blade profile (GlideScope ${ }^{\circledR}$ Lo Pro Adult, Verathon Medical Inc.,
Bothell, WA, USA). During this trial, the first-generation GVL was used, and although it is unlikely that using the newer blade would have resulted in substantially different results, the conclusions of this trial may not be applicable to the more recent design.

In summary, configuring an ETT with a distal $90^{\circ}$ angle decreased the average time to intubation with the GlideScope ${ }^{\circledR}$ by $13 \%$ and resulted in a significantly easier intubation. The ergonomics of the $60^{\circ}$ configuration used in this study may have impeded glottic visualization. The camber of the ETT did not impact the time to intubation. When using the $90^{\circ}$ angle, a high $(>90 \%)$ first attempt success rate was observed, even with a diverse set of operators and patients.

\section{References}

1 Cooper RM, Pacey JA, Bishop MJ, McCluskey SA. Early clinical experience with a new videolaryngoscope (GlideScope) in 728 patients. Can J Anesth 2005; 52: 191-8.

2 Doyle DJ. The GlideScope video laryngoscope. Anaesthesia 2005; 60: 414-5.

3 Cuchillo JV, Rodriguez MA. Considerations aimed at facilitating the use of the new GlideScope videolaryngoscope (Letter). Can J Anesth 2005; 52: 661.

4 The GlideScope ${ }^{\circledR}$ Video Intubation System - Operator \& Service Manual. Burnaby, BC, Canada: Saturn Biomedical Systems Inc.; 2003.

5 Bader SO, Heitz JW, Audu PB. Tracheal intubation with the GlideScope ${ }^{\circledR}$ videolaryngoscope, using a "J" shaped endotracheal tube (Letter). Can J Anesth 2006; 53: 634-5.

6 Cooper RM. Considerations aimed at facilitating the use of the new GlideScope videolaryngoscope (Letter, reply). Can J Anesth 2005; 52: 661-2.

7 Mallampati SR, Gatt SP, Gugino LD, et al. A clinical sign to predict difficult tracheal intubation: a prospective study. Can Anaesth Soc J 1985; 32: 429-34.

8 Cormack RS, Lehane J. Difficult tracheal intubation in obstetrics. Anaesthesia 1984; 39: 1105-11.

$9 \operatorname{Lim}$ TJ, $\operatorname{Lim} \Upsilon$, Lin EH. Evaluation of ease of intubation with the GlideScope or Macintosh laryngoscope by anaesthetists in simulated easy and difficult laryngoscopy. Anaesthesia 2005; 60: 180-3.

10 Turkstra TP, Craen RA, Pelz DM, Gelb AW. Cervical spine motion: a fluoroscopic comparison during intubation with lighted stylet, GlideScope, and Macintosh laryngoscope. Anesth Analg 2005; 101: 910-5.

11 Hardman JG, Wills JS, Aitkenhead AR. Factors determining the onset and course of hypoxemia during apnea: an investigation using physiological modelling. Anesth Analg 2000; 90: 619-24.

12 Falco-Molmeneu E, Ramirez-Montero F, Carregui- 
Tuson R, Santamaria-Arribas N, Gallen-Jaime T, VilaSanchez $M$. The modified Eschmann guide to facilitate tracheal intubation using the GlideScope ${ }^{\circledR}$ (Letter). Can J Anesth 2006; 53: 633-4.

13 Sun DA, Warriner CB, Parsons DG, Klein R, Umedaly HS, Moult $M$. The GlideScope ${ }^{\circledR}$ Video Laryngoscope: randomized clinical trial in 200 patients. Br J Anaesth 2005; 94: 381-4.

14 Rai MR, Dering A, Verghese C. The Glidescope system: a clinical assessment of performance. Anaesthesia 2005; 60: 60-4.

15 Halligan $M$, Charters $P$. A clinical evaluation of the Bonfils Intubation Fibrescope. Anaesthesia 2003; 58: 1087-91.

16 Holden JD. Hawthorne effects and research into professional practice. J Eval Clin Pract 2001; 7: 65-70.

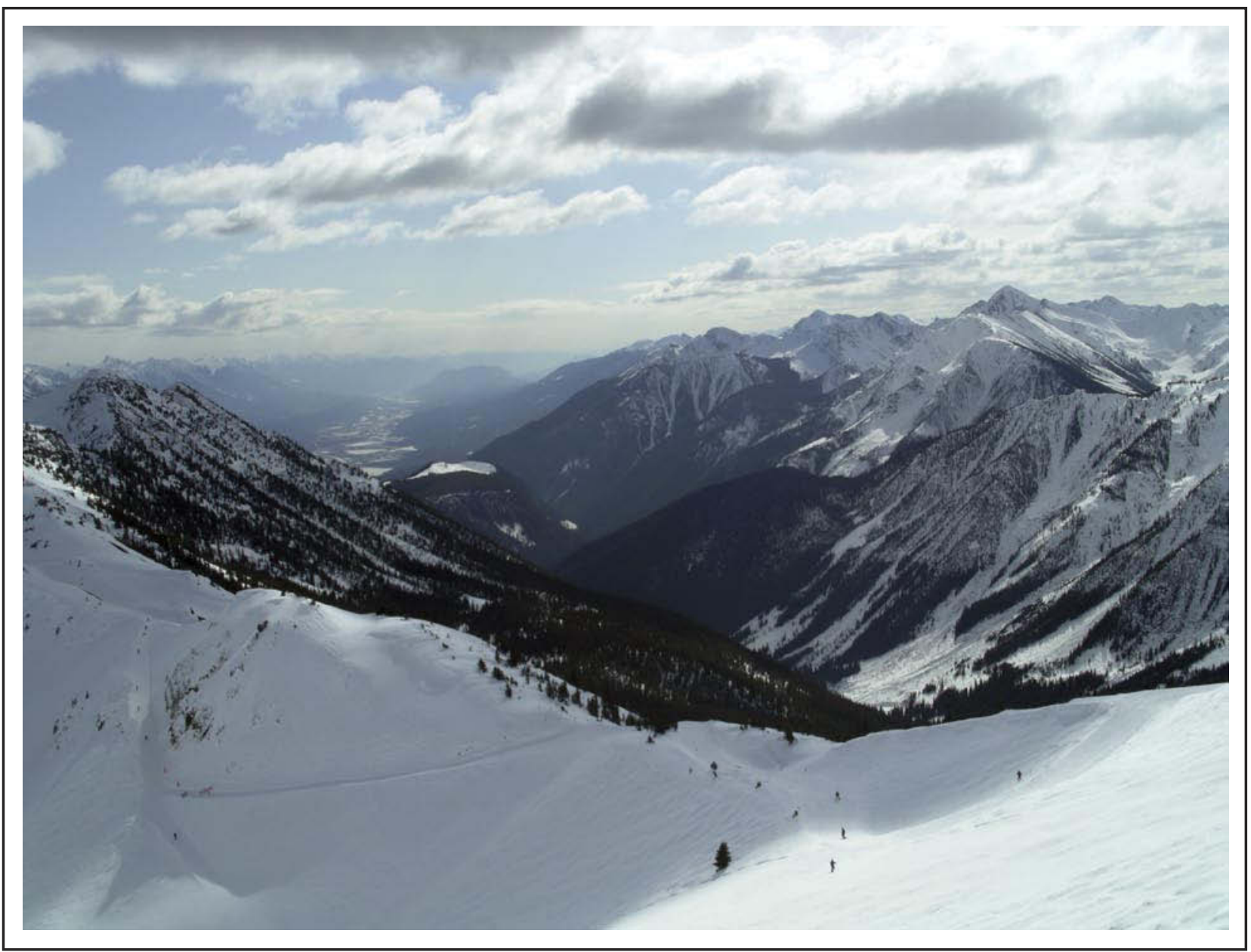

Kicking Horse Mountain - British Columbia 